\title{
Marrow fat and bone: review of clinical findings
}

\author{
Ann V. Schwartz* \\ Department of Epidemiology and Biostatistics, University of California San Francisco, San Francisco, CA, USA
}

\section{Edited by:}

Gustavo Duque, The University of Sydney, Australia

\section{Reviewed by:}

Melissa Orlandin Premaor, Federal University of Santa Maria, Brazil

Basem M. Abdallah, University of Southern Denmark, Denmark

*Correspondence:

Ann V. Schwartz, Department of Epidemiology and Biostatistics, University of California San Francisco, 550 16th Street, Box 0560, San Francisco, CA 94143, USA

e-mail:aschwartz@psg.ucsf.edu
With growing interest in the connection between fat and bone, there has been increased investigation of the relationship with marrow fat in particular. Clinical research has been facilitated by the development of non-invasive methods to measure bone marrow fat content and composition. Studies in different populations using different measurement techniques have established that higher marrow fat is associated with lower bone density and prevalent vertebral fracture. The degree of unsaturation in marrow fat may also affect bone health. Although other fat depots tend to be strongly correlated, marrow fat has a distinct pattern, suggesting separate mechanisms of control. Longitudinal studies are limited, but are crucial to understand the direct and indirect roles of marrow fat as an influence on skeletal health. With greater appreciation of the links between bone and energy metabolism, there has been growing interest in understanding the relationship between marrow fat and bone. It is well established that levels of marrow fat are higher in older adults with osteoporosis, defined by either low bone density or vertebral fracture. However, the reasons for and implications of this association are not clear. This review focuses on clinical studies of marrow fat and its relationship to bone.

Keywords: bone marrow fat, osteoporosis, bone marrow fat composition, magnetic resonance spectroscopy, bone marrow lipids

\section{MARROW FAT IN HUMANS}

Marrow fat is distinct from white adipose tissue and from brown adipose tissue $(1,2)$. The marrow fat depot also appears to be under separate control from other fat depots. Humans have virtually no marrow fat at birth, but marrow adiposity increases with age, particularly during the third decade of life. This well-known conversion of "red" to "yellow" marrow occurs to varying degrees at different skeletal sites, with a high percentage in the axial skeleton and a lower percentage in the vertebral bodies. For example, Justesen et al. reported that marrow fat in post-mortem iliac crest bone biopsies increased from $40 \%$ at age 30 to $68 \%$ by age 100 years (3). Both the size and number of adipocytes increase with age (4). The lifetime pattern of vertebral BMF accumulation appears to differ in men and women $(5,6)$. Griffith et al. found that before age 55 years, BMF is higher in men, but from ages $55-65$ years, women experience a steeper increase in BMF while men have a gradual increase in BMF with aging (5). As a result, BMF is higher in women at older ages compared with men.

Higher levels of marrow fat are known to occur in humans in conditions of starvation $(7,8)$, alcoholism (9), spinal cord injury (10), and prolonged bed rest (11), conditions that are also associated with reduced bone density. Medications that increase marrow fat include glucocorticoids (12) and thiazolidinediones (TZDs) (13), highlighting the interconnection of bone formation and marrow fat accumulation.

The age-related changes in marrow fat and the increases with specific pathologies have been recognized for years, but progress in understanding its role and functions has been relatively recent. In vitro and animal models have provided new insight into the connection between marrow fat and bone in particular, and these findings have been extensively reviewed (14-17). Briefly, studies indicate that marrow fat may function as an indirect marker of changes in bone and may also play a direct role in bone health. Changes in the differentiation programs that give rise to osteoblasts and adipocytes from mesenchymal stem cells in the marrow can favor adipogenesis over osteoblastogenesis, leading to increased marrow fat with reduced bone formation. Major control of mesenchymal stem cell differentiation resides with peroxisome proliferator-activated receptor (PPAR) $-\gamma$ for adipogenesis and runt-related transcription factor 2 (RUNX2) for osteogenesis, with the canonical Wnt $/ \beta$-catenin pathway playing a central role. As with other fat depots, marrow fat is an endocrine organ and may directly influence the survival and function of osteoblasts and osteoclasts through the release of cytokines, adipokines, and fatty acids.

\section{NON-INVASIVE MEASUREMENT OF MARROW FAT PROPELS CLINICAL RESEARCH}

Progress in clinical studies of marrow fat and bone has been greatly facilitated by recent technical advances in our ability to non-invasively measure marrow fat. Historically, clinical measures of marrow fat required a biopsy. More recently, non-invasive measurements have become available in the research setting although these are not generally used clinically. Two techniques using magnetic resonance imaging (MRI) are widely used to assess fat in the bone marrow: magnetic resonance spectroscopy (MRS) and T1-weighted MRI. Dual energy QCT can also be used to quantify marrow fat. However, dual energy scans require relatively high levels of radiation. Single energy QCT does not give a reliable measure of marrow fat.

In MRS measurements, marrow fat is expressed as a percentage rather than an absolute value. For evaluation of vertebral marrow 
fat, the measurement is acquired on one or more of the lumbar vertebral bodies (L1-L4). A single voxel is placed in the center of the vertebral body (Figure 1) (18). The calculation of marrow fat varies slightly across studies. The percent marrow fat can be calculated using the large lipid peak at $1.3 \mathrm{ppm}$ (saturated lipids), ignoring the much smaller lipid peaks at 5.3 (unsaturated lipids) and 2.0 (residual lipids) $(18,19)$. Fat content is then calculated as: fat content $=\left[\left(I_{\text {fat }} /\left(I_{\text {fat }}+I_{\text {water }}\right)\right] \times 100 \%\right.$. With higher resolution MRI ( $3 \mathrm{~T})$, fat content has also been reported using three of these lipid peaks (20). Fat content is then calculated as: fat content $=\left[\left(I_{\mathrm{UL}}+I_{\mathrm{RL}}+I_{\mathrm{SL}}\right) /\left(I_{\mathrm{UL}}+I_{\mathrm{RL}}+I_{\mathrm{SL}}+I_{\text {water }}\right)\right] \times 100 \%$.

Some studies have relied on one vertebral level while others have reported an average of several levels. The fat content tends to increase from L1 to $\mathrm{L} 4(18,21)$. Thus, reported marrow fat levels may vary across studies depending on which levels were included. In postmenopausal women, vertebral marrow fat levels at separate vertebral levels from L1 to L4 were highly correlated (18). Although trabecular spine vBMD is measured at L1 and L2, the correlation between BMF and trabecular spine vBMD in older women did not vary substantially when each vertebral level was considered separately. The correlations with trabecular spine BMD (L1-L2) were: -0.23 for BMF measured at L1, -0.20 for $\mathrm{L} 2,-0.23$ for $\mathrm{L} 3,-0.28$ at L4, and -0.26 for the mean L1-L4 (21).

BMF measured by T1-weighted MRI is also expressed as a percentage. Fat fraction is calculated for the whole body and for specific regions, often the pelvic region, from a whole-body MRI (22). In contrast to MRS, the T1-weighted MRI is semi-quantitative and may also have errors due to partial volume effects. However, MRS is limited to measurement of a small area of the total marrow. Shen et al. compared measurements of BMF using MRS, T1-weighted MRI, and a third MR-based method, the Dixon method, and found good correlations among the different methods (23).

With MRS, it is also possible to quantify the smaller lipid peaks and assess the degree of saturation of the lipids in marrow (Figure 1). Yeung et al. introduced the unsaturation index, using spectra acquired on a $1.5 \mathrm{~T}$ scanner (24). The signal amplitude at about $5.3 \mathrm{ppm}$ (olefinic) was compared to combined signal amplitudes at 5.3, 2.0, 1.3, and $0.9 \mathrm{ppm}$, to obtain an unsaturation index. Degree of lipid unsaturation has also been assessed using spectra acquired with a $3 \mathrm{~T}$ scanner, with a formula that compares signal amplitude at $5.3 \mathrm{ppm}$ to the combined amplitudes at $5.3 \mathrm{ppm}$ (UL), $2.0 \mathrm{ppm}$ (RL), and $1.3 \mathrm{ppm}$ (SL), $\mathrm{UL}(\%)=\left[I_{\mathrm{UL} /}\left(I_{\mathrm{UL}}+I_{\mathrm{RL}}+I_{\mathrm{SL}}\right)\right] \times 100 \%$ (20). Resolution of the smaller peaks is difficult, even at $3 \mathrm{~T}$, and the unsaturation index should be utilized as a relative index for comparing lipid composition rather than an absolute measure of marrow lipid unsaturation.

\section{AN INVERSE RELATIONSHIP BETWEEN MARROW FAT AND BONE DENSITY}

Cross-sectional studies in humans using different methods to assess bone density and marrow fat have found that lower bone density is accompanied by higher marrow fat. In 1971, Meunier et al. reported that samples from the iliac crest in women with osteoporosis had a pronounced accumulation of adipocytes, relative to age-matched controls (25). Other studies using bone biopsy to assess marrow fat have also reported a relationship with osteoporosis $(3,25,26)$. Histomorphometry has shown a negative association between bone marrow fat and bone formation rates (26).

Studies using non-invasive imaging methods to assess BMF have also reported an association between higher BMF and lower $\operatorname{BMD}(18,19,21,27,28)$. Most studies of BMF and bone density have relied on DXA measurements of bone. Negative associations between BMF and BMD by DXA have been reported for men (19) and women (27). Although bone density by DXA is a robust predictor of fracture risk, the DXA measurements provide only areal estimates of density, cannot distinguish cortical and trabecular bone, and are thus limited for purposes of etiologic research. QCT measurements of bone can potentially provide greater insight into

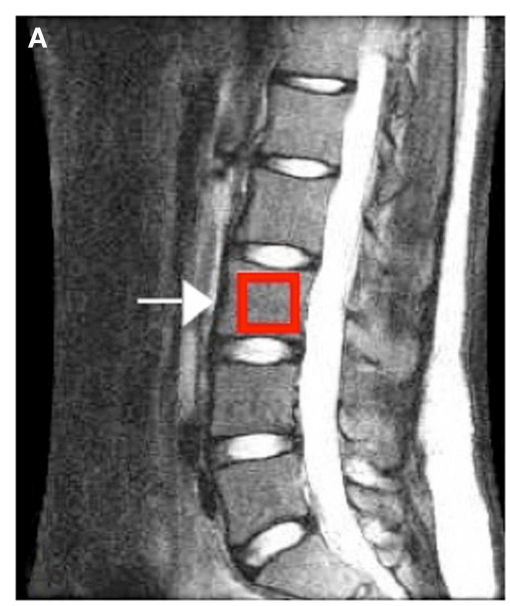

FIGURE 1 | Measurement of vertebral bone marrow fat using magnetic resonance spectroscopy. (A) Positioning of box in the middle of the vertebral body (L3 as example). (B) Example spectrum in vertebral bone marrow (3T). Four peaks were well resolved: olefinic, double bond
B

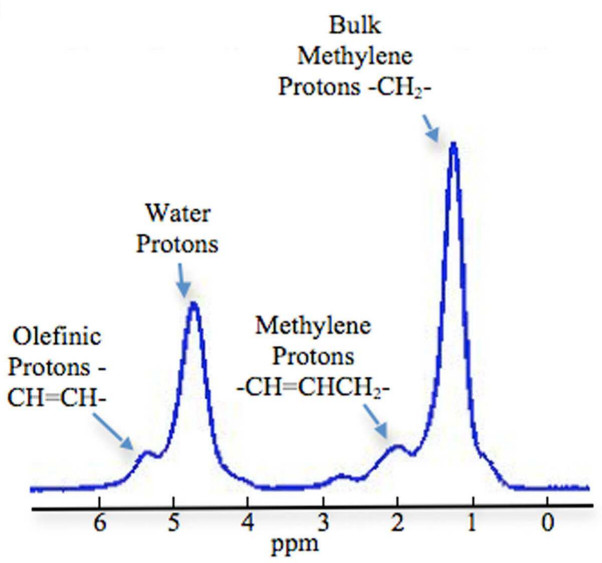

$-\mathrm{CH}=\mathrm{CH}$ - protons at $5.31 \mathrm{ppm}$, water protons at $4.65 \mathrm{ppm}$, the $\mathrm{CH}_{2}$ methylene protons $\alpha$ to a double bond $\left(-\mathrm{CH}=\mathrm{CHCH}_{2}-\right)$, at $2.03 \mathrm{ppm}$, and the bulk $\mathrm{CH}_{2}$ methylene protons at $1.3 \mathrm{ppm}$. Adapted with permission from Ref. (18) 
the aspects of bone metabolism that are associated with BMF. In a study of postmenopausal women with and without type 2 diabetes, trabecular spine vBMD and BMF were negatively correlated in both groups (29). In the Iceland AGES-Reykjavik cohort of older adults, higher BMF was associated with lower trabecular spine, total hip and femoral neck vBMD, and reduced vertebral compressive strength, derived from QCT, in women (21). A difference of about $+8 \%$ in BMF was associated with differences in trabecular vBMD of $-10.5 \%$ (95\% CI: -17.2 to $-3.2 \%)$ at the spine, $-7.08 \%(-12.51$ to -1.31$)$ at femoral neck, and $-3.95 \%$ $(-7.64$ to $-0.12 \%)$ at total hip. In men, BMF was also negatively associated with trabecular spine vBMD and with vertebral compressive strength, but associations were not statistically significant. In men, there was no evident association between BMF and trabecular vBMD at the hip. No associations were seen with cortical vBMD and BMF at either hip site in men or women.

These cross-sectional studies indicate that higher BMF is associated with reduced bone density and strength, but longitudinal data on these relationships are limited. Importantly, Griffith et al. reported that higher BMF at the hip predicts femoral neck bone loss, measured by DXA, over 4 years in postmenopausal women (mean age 74 years) (30). Women with BMF above and below the median experienced average bone loss of 1.6 and $4.7 \%$, respectively. Changes in BMF were not measured in this study.

DXA and QCT measurements of bone are both vulnerable to artificially low readings in the presence of higher $\operatorname{BMF}(31,32)$. Blake et al. estimated that BMF and BMD by DXA are still negatively correlated even after the artificial lowering of BMD with higher BMF is taken into account (32). It is also reassuring that studies using biopsy methods rather than imaging to assess bone and marrow fat have reported negative associations $(3,25,26)$.

\section{MARROW FAT AND FRACTURE}

Studies have reported a relationship between higher BMF and prevalent vertebral fracture $(3,21,33,34)$. Justesen et al. reported higher marrow fat, measured in iliac crest biopsies, in 26 women with prevalent vertebral fracture compared with age-matched controls (63 vs. $54 \%, p=0.02$ ) (3). Wehrli et al. also found higher marrow fat in those with prevalent vertebral deformities in a study of older adults (106 women, 33 men) (33). Mean BMF at the spine was 55 and $45 \%(p<0.001)$ in those with and without a baseline vertebral fracture, respectively, and remained statistically different after adjustment for spine BMD by DXA. In AGES-Reykjavik, higher vertebral BMF was associated with prevalent vertebral fracture ( 56.9 vs. $53.7 \%, p=0.01)$, in models adjusted for age, gender, and trabecular spine vBMD (21). A history of non-vertebral fracture was not associated with BMF in postmenopausal women (20) or in the Iceland AGES cohort (21). To date, studies of BMF and incident fracture are not available.

\section{MARROW FAT AND SCLEROSTIN}

Sclerostin is a product of osteocytes that is a negative regulator of bone formation and the target of new therapies for osteoporosis. Some $(35,36)$ but not other $(37,38)$, longitudinal studies have reported an increased risk of incident fracture with higher sclerostin. Somewhat surprisingly, higher circulating sclerostin levels are associated with higher bone density $(35,37-40)$. Among older adults in the Iceland AGES-Reykjavik cohort, serum sclerostin was positively associated with vertebral bone marrow fat in men, but not in women (41). These results indicate a possible relationship between osteocyte activity and bone marrow fat.

\section{POSSIBLE GENDER DIFFERENCES IN THE RELATIONSHIP BETWEEN MARROW FAT AND BONE}

Cross-sectional results from the Iceland AGES-Reykjavik cohort suggest that the relationships between BMF, bone density, and bone strength, as well as sclerostin, may differ by gender. Stronger correlations were observed between BMF and bone in women, but BMF was associated with prevalent vertebral fracture in men (21). These gender differences may be due to the effects of sex hormone levels on BMF and bone. Estrogen as well as testosterone levels are higher in older men compared with postmenopausal women. There is evidence from animal and clinical studies that sex hormone levels affect BMF. Rodents experience increased marrow adiposity with ovariectomy along with decreased bone mass (42), and conversely estrogen replacement reduces bone marrow adipogenesis in older mice (43). Female rats receiving testosterone have also been shown to have lower BMF content (44). In postmenopausal women, treatment with transdermal estrogen reduced BMF measured in bone biopsies (45). Studies of the relationship between endogenous estrogen or testosterone levels and BMF in older adults are not currently available.

\section{MARROW FAT AND CORTICAL POROSITY}

Investigation of the relationship between marrow fat and bone has focused on the amount and composition of fat in the marrow cavity. With the growing appreciation of cortical porosity as a distinct factor in bone health and strength, there is now also interest in assessing the presence of marrow fat within cortical pores. New techniques using high-resolution peripheral computed quantitative tomography (HRpQCT) and 3 T MRS show promise in distinguishing marrow and blood vessels in pore space (46). Future studies that can identify the extent of marrow fat in cortical pores may help to identify underlying mechanisms determining porosity.

\section{LIPID COMPOSITION OF MARROW FAT ALSO ASSOCIATED WITH BONE DENSITY AND FRACTURE}

The composition as well as the quantity of marrow fat may be relevant for skeletal health (47). The relative amounts of saturated and unsaturated lipids in marrow fat can be measured non-invasively with MR spectroscopy, allowing exploration of this aspect of marrow fat composition. Small studies suggest that a lower proportion of unsaturated lipids in vertebral marrow fat may be associated with reduced BMD and greater prevalence of fracture $(20,24)$. Yeung et al. assessed vertebral marrow fat content and composition in 12 premenopausal controls and 50 older women $(60+)$ without evidence of vertebral fracture (24). The older women included those with normal $(n=15)$, low $(n=15)$, and osteoporotic $(n=20)$ spine BMD. Consistent with other reports, marrow fat content was $29 \%$ in young control women, and 56, 63, and $65 \%$ in older women with normal, low, and osteoporotic $\mathrm{BMD}$, respectively. The highest proportion of unsaturated lipids in marrow fat was found in the younger controls $(0.127)$ and the 
lowest proportion in older women with osteoporotic spine BMD (0.091). Unsaturation levels in older women with normal and osteopenic BMD were 0.114 and 0.097 , respectively. The unsaturation level and marrow fat content were negatively correlated $(r=-0.53, p<0.0001)$. In a study of postmenopausal women $(n=69)$, Patsch et al. reported an association between history of fracture and lower unsaturation levels, even after adjustment for spine vBMD ( $-1.7 \%$; $95 \%$ CI -2.8 to $-0.5 \%)$ (20).

Marrow fat specimens obtained by iliac crest aspiration during hip surgery in 24 postmenopausal women were analyzed with high-resolution (11.7 T) MR (48). Similar to above studies using non-invasive measurements, the unsaturation level was lower in those with low BMD compared to those with normal BMD. However, in another study using marrow fat specimens obtained during elective orthopedic surgery, gas chromatography analysis of fatty acids found similar composition in those with normal, low, and osteoporotic BMD in all specimens $(n=126)$, in those from the tibia $(n=80)$, and in those from the proximal femur $(n=32)(2)$.

\section{MARROW FAT, OTHER FAT DEPOTS, AND DIABETES}

The role of marrow fat, including the underlying mechanisms of its relationship to bone, remains poorly understood. One important area of clinical investigation has considered the relationship between marrow fat and other fat depots. The sizes of adipose depots outside the marrow, including total body, visceral, and subcutaneous depots tend to be strongly correlated with each other and with body size. In contrast, BMF tends to be independent of overall body size $(3,22,49-51)$ and total body fat $(22,51)$. However, a study in the CARDIA cohort $(n=210)$ found a negative correlation between BMI and hip BMAT $(-0.38$; 95\% CI -0.53 to $-0.21)(52)$ and a large study $(n=455)$ of men and women aged 18-88 years identified a positive correlation between total body fat and pelvic BMAT $(r=0.24, p<0.01)$ (53). In contrast, marrow fat appears to be consistently elevated in patients with anorexia nervosa who have very low levels of total body fat (7).

Evidence regarding the relationship between visceral adipose tissue and marrow fat is inconsistent. Positive correlations between BMF and visceral adipose tissue $(r=0.34, p=0.02)$ have been reported in obese premenopausal women (50) and in the CARDIA cohort of middle-aged adults for pelvic BMAT $(r=0.17, p<0.05)$ but not hip BMAT $(r=0.14, p>0.05)$ (52). However, other studies have not found an association $(22,29,49)$. In a large cross-sectional study $(n=455)$, there was a modest but statistically significant negative correlation between VAT and pelvic BMAT $(r=-0.10$, $p<0.001)(53)$.

Marrow fat is higher with diabetes in rodent models of type 1 diabetes (54), but there have been few clinical studies of this relationship and results are inconsistent. In a study of 16 adult men and women with type 1 diabetes (T1D) and 12 healthy controls, vertebral BMF did not differ by diabetes status (55). In postmenopausal women with $(n=13)$ and without $(n=13)$ type 2 diabetes (T2D), those with T2D had higher BMF (69.3 vs. $67.5 \%, p=0.31$ ), but the difference was not statistically significant (29). However, in the women with T2D, BMF was positively correlated with A1C $(r=0.82, p<0.05)$. A study in 156 older men reported higher BMF in those with T2D (59 vs. 55\%, $p=0.03$ ) (56). Marrow fat composition may also differ by diabetes status. Patsch et al. found that T2D was associated with lower unsaturation levels of vertebral marrow fat $(-1.3 \%$; $95 \% \mathrm{CI}-2.3$ to $-0.2 \%)$ in postmenopausal women (20).

\section{WEIGHT LOSS, BONE LOSS, AND MARROW FAT}

Weight loss in older adults is known to increase bone loss and fracture risk, even among those who are overweight or obese $(57,58)$. In states of extreme under-nutrition, BMF is increased while other fat depots are depleted (7), but little is currently known about the clinical effects of weight loss on BMF in overweight or obese adults.

In a short-term (13-week) study of diet-induced weight loss in 55 women and 17 men, age 19-46 years, participants lost an average of $9.2 \mathrm{~kg}$ (about 9\% of body weight) (59). Pelvic BMAT, measured by whole-body MRI, also decreased by an average of $17.8 \mathrm{~cm}^{3}$ (about $8 \%$ ). However, total body BMD increased by $0.01 \mathrm{~g} / \mathrm{cm}^{2}$ (about 1\%); the lack of bone loss in spite of substantial weight loss may be due to the younger age of participants, use of whole body BMD rather than hip BMD, and/or the short follow-up time. In a 12 -week weight loss study $(n=10)$, participants lost $5.2 \mathrm{~kg}$ on average, but did not experience a statistically significant change in pelvic or total BMF, measured by MRI (60). In a study of the effects of bariatric surgery, changes in vertebral BMF were assessed before and 6 months after surgery in 11 morbidly obese women who lost on average $36.5 \%$ of total body fat. Schafer et al. reported little change in vertebral BMF $(+0.9 \%$; $95 \% \mathrm{CI}-10.0$ to $+11.7 \%, p=0.84)$ in women without diabetes $(n=5)$ and an apparent decrease in BMF $(-7.5 \%$; $95 \%$ CI -15.2 to $+0.1 \%, p=0.05)$ in those with T2D $(n=6)(61)$. Bariatric surgery can dramatically improve insulin sensitivity (62) and the decrease in $\mathrm{BMF}$ in the $\mathrm{T} 2 \mathrm{D}$ women may reflect a response to changes in diabetes status. Women did lose bone after the surgery at the total hip (4.1\%), femoral neck (5.2\%), and spine $(7.4 \%)$. However, this bone loss, induced by the substantial weight loss of bariatric surgery, was not accompanied by increases in BMF.

These findings suggest that changes in bone and in marrow fat are not necessarily linked and that their inter-relationship is dependent on other factors including diabetes status. Further investigation of the dynamic relationships among weight loss, insulin resistance, bone loss, and changes in marrow fat promises to give us a better understanding of the interplay of marrow fat and bone.

\section{SUMMARY}

Osteoporosis is an important health issue, contributing substantially to morbidity and mortality among older adults. Health care costs for osteoporosis-related fractures in the United States were estimated as $\$ 19$ billion in 2005 and are expected to increase $50 \%$ by 2025 with the growth of the older population (63). Animal studies have identified BMF as part of the dynamic processes influencing bone density and strength, and cross-sectional clinical studies have confirmed relationships between higher BMF, lower bone density, and increased prevalence of vertebral fracture in older men and women while suggesting gender differences in the strength of these relationships. This accumulating evidence points to the potential for BMF to play a diagnostic and therapeutic role in the prevention of osteoporosis $(64,65)$. At this 
juncture, longitudinal data are needed to determine the relationship between changes in BMF and bone, particularly in the context of weight loss and changes in other fat depots, and to disentangle the gender differences observed in cross-sectional studies. A better understanding of the role of BMF in humans may lead to new avenues to promote bone formation and thus prevent and treat osteoporosis.

\section{REFERENCES}

1. Scheller EL, Rosen CJ. What's the matter with MAT? Marrow adipose tissue, metabolism, and skeletal health. Ann N Y Acad Sci (2014) 1311:14-30. doi:10.1111/nyas. 12327

2. Griffith JF, Yeung DK, Ahuja AT, Choy CW, Mei WY, Lam SS, et al. A study of bone marrow and subcutaneous fatty acid composition in subjects of varying bone mineral density. Bone (2009) 44:1092-6. doi:10.1016/j.bone.2009.02.022

3. Justesen J, Stenderup K, Ebbesen EN, Mosekilde L, Steiniche T, Kassem M. Adipocyte tissue volume in bone marrow is increased with aging and in patients with osteoporosis. Biogerontology (2001) 2:165-71. doi:10.1023/A: 1011513223894

4. Rozman C, Feliu E, Berga L, Reverter JC, Climent C, Ferran MJ. Age-related variations of fat tissue fraction in normal human bone marrow depend both on size and number of adipocytes: a stereological study. Exp Hematol (1989) 17:34-7.

5. Griffith JF, Yeung DK, Ma HT, Leung JC, Kwok TC, Leung PC. Bone marrow fat content in the elderly: a reversal of sex difference seen in younger subjects. J Magn Reson Imaging (2012) 36:225-30. doi:10.1002/jmri.23619

6. Roldan-Valadez E, Pina-Jimenez C, Favila R, Rios C. Gender and age groups interactions in the quantification of bone marrow fat content in lumbar spine using 3T MR spectroscopy: a multivariate analysis of covariance (MANCOVA). Eur J Radiol (2013) 82:e697-702. doi:10.1016/j.ejrad.2013.07.012

7. Bredella MA, Fazeli PK, Miller KK, Misra M, Torriani M, Thomas BJ, et al. Increased bone marrow fat in anorexia nervosa. J Clin Endocrinol Metab (2009) 94:2129-36. doi:10.1210/jc.2008-2532

8. Ecklund K, Vajapeyam S, Feldman HA, Buzney CD, Mulkern RV, Kleinman PK, et al. Bone marrow changes in adolescent girls with anorexia nervosa. J Bone Miner Res (2010) 25:298-304. doi:10.1359/jbmr.090805

9. Maurel DB, Boisseau N, Benhamou CL, Jaffre C. Alcohol and bone: review of dose effects and mechanisms. Osteoporosis Int (2012) 23:1-16. doi:10.1007/ s00198-011-1787-7

10. Minaire P, Edouard C, Arlot M, Meunier PJ. Marrow changes in paraplegic patients. Calcif Tissue Int (1984) 36:338-40. doi:10.1007/BF02405340

11. Trudel G, Payne M, Madler B, Ramachandran N, Lecompte M, Wade C, et al. Bone marrow fat accumulation after 60 days of bed rest persisted 1 year after activities were resumed along with hematopoietic stimulation: the women international space simulation for exploration study. J Appl Physiol (1985) 2009(107):540-8. doi:10.1152/japplphysiol.91530.2008

12. Vande Berg BC, Malghem J, Lecouvet FE, Devogelaer JP, Maldague B, Houssiau FA. Fat conversion of femoral marrow in glucocorticoid-treated patients: a crosssectional and longitudinal study with magnetic resonance imaging. Arthritis Rheum (1999) 42:1405-11. doi:10.1002/1529-0131(199907)42:7<1405::AIDANR14>3.0.CO;2-W

13. Grey A, Beckley V, Doyle A, Fenwick S, Horne AM, Gamble GD, et al. Pioglitazone increases bone marrow fat in type 2 diabetes: results from a randomized controlled trial. Eur J Endocrinol (2012) 166:1087-91. doi:10.1530/EJE-11-1075

14. Bermeo S, Gunaratnam K, Duque G. Fat and bone interactions. Curr Osteoporos Rep (2014) 12:235-42. doi:10.1007/s11914-014-0199-y

15. Rosen CJ, Ackert-Bicknell C, Rodriguez JP, Pino AM. Marrow fat and the bone microenvironment: developmental, functional, and pathological implications. Crit Rev Eukaryot Gene Expr (2009) 19:109-24. doi:10.1615/ CritRevEukarGeneExpr.v19.i2.20

16. Lecka-Czernik B. Marrow fat metabolism is linked to the systemic energy metabolism. Bone (2012) 50:534-9. doi:10.1016/j.bone.2011.06.032

17. Nuttall ME, Shah F, Singh V, Thomas-Porch C, Frazier T, Gimble JM. Adipocytes and the regulation of bone remodeling: a balancing act. Calcif Tissue Int (2014) 94:78-87. doi:10.1007/s00223-013-9807-6

18. Li X, Kuo D, Schafer AL, Porzig A, Link TM, Black D, et al. Quantification of vertebral bone marrow fat content using 3 Tesla MR spectroscopy: reproducibility, vertebral variation, and applications in osteoporosis. J Magn Reson Imaging (2011) 33:974-9. doi:10.1002/jmri.22489

19. Griffith JF, Yeung DK, Antonio GE, Lee FK, Hong AW, Wong SY, et al. Vertebral bone mineral density, marrow perfusion, and fat content in healthy men and men with osteoporosis: dynamic contrast-enhanced MR imaging and MR spectroscopy. Radiology (2005) 236:945-51. doi:10.1148/radiol.2363041425

20. Patsch JM, Li X, Baum T, Yap SP, Karampinos DC, Schwartz AV, et al. Bone marrow fat composition as a novel imaging biomarker in postmenopausal women with prevalent fragility fractures. J Bone Miner Res (2013) 28:1721-8. doi:10.1002/jbmr.1950

21. Schwartz AV, Sigurdsson S, Hue TF, Lang TF, Harris TB, Rosen CJ, et al. Vertebral bone marrow fat associated with lower trabecular BMD and prevalent vertebral fracture in older adults. J Clin Endocrinol Metab (2013) 98:2294-300. doi:10.1210/jc.2012-3949

22. Shen W, Chen J, Punyanitya M, Shapses S, Heshka S, Heymsfield SB. MRImeasured bone marrow adipose tissue is inversely related to DXA-measured bone mineral in Caucasian women. Osteoporosis Int (2007) 18:641-7. doi:10. 1007/s00198-006-0285-9

23. Shen W, Gong X, Weiss J, Jin Y. Comparison among T1-weighted magnetic resonance imaging, modified Dixon method, and magnetic resonance spectroscopy in measuring bone marrow fat. J Obes (2013) 2013:298675. doi:10.1155/2013/298675

24. Yeung DK, Griffith JF, Antonio GE, Lee FK, Woo J, Leung PC. Osteoporosis is associated with increased marrow fat content and decreased marrow fat unsaturation: a proton MR spectroscopy study. J Magn Reson Imaging (2005) 22:279-85. doi:10.1002/jmri.20367

25. Meunier P, Aaron J, Edouard C, Vignon G. Osteoporosis and the replacement of cell populations of the marrow by adipose tissue. A quantitative study of 84 iliac bone biopsies. Clin Orthop Relat Res (1971) 80:147-54. doi:10.1097/00003086-197110000-00021

26. Verma S, Rajaratnam JH, Denton J, Hoyland JA, Byers RJ. Adipocytic proportion of bone marrow is inversely related to bone formation in osteoporosis. J Clin Pathol (2002) 55:693-8. doi:10.1136/jcp.55.9.693

27. Griffith JF, Yeung DK, Antonio GE, Wong SY, Kwok TC, Woo J, et al. Vertebral marrow fat content and diffusion and perfusion indexes in women with varying bone density: MR evaluation. Radiology (2006) 241:831-8. doi:10.1148/radiol. 2413051858

28. Shen W, Chen J, Gantz M, Punyanitya M, Heymsfield SB, Gallagher D, et al. MRI-measured pelvic bone marrow adipose tissue is inversely related to DXAmeasured bone mineral in younger and older adults. Eur J Clin Nutr (2012) 66(9):983-8. doi:10.1038/ejcn.2012.35

29. Baum T, Yap SP, Karampinos DC, Nardo L, Kuo D, Burghardt AJ, et al. Does vertebral bone marrow fat content correlate with abdominal adipose tissue, lumbar spine bone mineral density, and blood biomarkers in women with type 2 diabetes mellitus? J Magn Reson Imaging (2012) 35:117-24. doi:10.1002/jmri.22757

30. Griffith JF, Yeung DK, Leung JC, Kwok TC, Leung PC. Prediction of bone loss in elderly female subjects by MR perfusion imaging and spectroscopy. Eur Radiol (2011) 21:1160-9. doi:10.1007/s00330-010-2054-6

31. Glüer CC, Reiser UJ, Davis CA, Rutt BK, Genant HK. Vertebral mineral determination by quantitative computed tomography (QCT): accuracy of single and dual energy measurements. J Comput Assist Tomogr (1988) 12:242-58. doi:10.1097/00004728-198803000-00013

32. Blake GM, Griffith JF, Yeung DK, Leung PC, Fogelman I. Effect of increasing vertebral marrow fat content on BMD measurement, T-Score status and fracture risk prediction by DXA. Bone (2009) 44:495-501. doi:10.1016/j.bone.2008. 11.003

33. Wehrli FW, Hopkins JA, Hwang SN, Song HK, Snyder PJ, Haddad JG. Crosssectional study of osteopenia with quantitative MR imaging and bone densitometry. Radiology (2000) 217:527-38. doi:10.1148/radiology.217.2.r00nv20527

34. Schellinger D, Lin CS, Hatipoglu HG, Fertikh D. Potential value of vertebral proton MR spectroscopy in determining bone weakness. AJNR Am J Neuroradiol (2001) 22:1620-7.

35. Arasu A, Cawthon PM, Lui LY, Do TP, Arora PS, Cauley JA, et al. Serum sclerostin and risk of hip fracture in older Caucasian women. J Clin Endocrinol Metab (2012) 97:2027-32. doi:10.1210/jc.2011-3419

36. Ardawi MS, Rouzi AA, Al-Sibiani SA, Al-Senani NS, Qari MH, Mousa SA. High serum sclerostin predicts the occurrence of osteoporotic fractures in postmenopausal women: the CEOR study. J Bone Miner Res (2012) 27:2592-602. doi:10.1002/jbmr.1718 
37. Szulc P, Bertholon C, Borel O, Marchand F, Chapurlat R. Lower fracture risk in older men with higher sclerostin concentration: a prospective analysis from the MINOS study. J Bone Miner Res (2013) 28:855-64. doi:10.1002/jbmr.1823

38. Garnero P, Sornay-Rendu E, Munoz F, Borel O, Chapurlat RD. Association of serum sclerostin with bone mineral density, bone turnover, steroid and parathyroid hormones, and fracture risk in postmenopausal women: the OFELY study. Osteoporosis Int (2013) 24:489-94. doi:10.1007/s00198-012-1978-x

39. Amrein K, Amrein S, Drexler C, Dimai HP, Dobnig H, Pfeifer K, et al. Sclerostin and its association with physical activity, age, gender, body composition, and bone mineral content in healthy adults. J Clin Endocrinol Metab (2012) 97:148-54. doi:10.1210/jc.2011-2152

40. Sheng Z, Tong D, Ou Y, Zhang H, Zhang Z, Li S, et al. Serum sclerostin levels were positively correlated with fat mass and bone mineral density in central south Chinese postmenopausal women. Clin Endocrinol (Oxf) (2012) 76:797-801. doi:10.1111/j.1365-2265.2011.04315.x

41. Ma YH, Schwartz AV, Sigurdsson S, Hue TF, Lang TF, Harris TB, et al. Circulating sclerostin associated with vertebral bone marrow fat in older men but not women. J Clin Endocrinol Metab (2014) 99:E2584-90. doi:10.1210/jc.2013-4493

42. Sottile V, Seuwen K, Kneissel M. Enhanced marrow adipogenesis and bone resorption in estrogen-deprived rats treated with the PPARgamma agonist BRL49653 (rosiglitazone). Calcif Tissue Int (2004) 75:329-37. doi:10.1007/ s00223-004-0224-8

43. Elbaz A, Rivas D, Duque G. Effect of estrogens on bone marrow adipogenesis and Sirtl in aging C57BL/6J mice. Biogerontology (2009) 10:747-55. doi:10.1007/s10522-009-9221-7

44. Tamura N, Kurabayashi T, Nagata H, Matsushita H, Yahata T, Tanaka K. Effects of testosterone on cancellous bone, marrow adipocytes, and ovarian phenotype in a young female rat model of polycystic ovary syndrome. Fertil Steril (2005) 84(Suppl 2):1277-84. doi:10.1016/j.fertnstert.2005.06.017

45. Syed FA, Oursler MJ, Hefferanm TE, Peterson JM, Riggs BL, Khosla S. Effects of estrogen therapy on bone marrow adipocytes in postmenopausal osteoporotic women. Osteoporosis Int (2008) 19:1323-30. doi:10.1007/s00198-008-0574-6

46. Parrish R, Rivoire J, Han M, Schafer AL, Link T, Krug R, et al. Multi-modality in vivo imaging identifies marrow and vasculature within pathological cortical porosity. American Society for Bone Mineral Research Annual Meeting. Houston, TX (2014).

47. Devlin MJ. Bone marrow composition, diabetes, and fracture risk: more bad news for saturated fat. J Bone Miner Res (2013) 28:1718-20. doi:10.1002/jbmr. 2013

48. Li X, Shet K, Rodriguez JP, Pino AM, Kurhanewicz J, Schwartz A, et al. Unsaturation level decreased in bone marrow lipids of postmenopausal women with low bone density using high resolution HRMAS NMR. J Bone Miner Res (2012) 27(Suppl 1). Available from: http://www.asbmr.org/Meetings/AnnualMeeting/ AbstractDetail.aspx?aid=2532d759-fe47-46a8-adf9-76d75581daeb

49. Di Iorgi N, Rosol M, Mittelman SD, Gilsanz V. Reciprocal relation between marrow adiposity and the amount of bone in the axial and appendicular skeleton of young adults. J Clin Endocrinol Metab (2008) 93:2281-6. doi:10.1210/jc.2007-2691

50. Bredella MA, Torriani M, Ghomi RH, Thomas BJ, Brick DJ, Gerweck AV, et al. Vertebral bone marrow fat is positively associated with visceral fat and inversely associated with IGF-1 in obese women. Obesity (Silver Spring) (2010) 19:49-53. doi:10.1038/oby.2010.106

51. Di Iorgi N, Mo AO, Grimm K, Wren TA, Dorey F, Gilsanz V. Bone acquisition in healthy young females is reciprocally related to marrow adiposity. J Clin Endocrinol Metab (2010) 95:2977-82. doi:10.1210/jc.2009-2336

52. Shen W, Scherzer R, Gantz M, Chen J, Punyanitya M, Lewis CE, et al. Relationship between MRI-measured bone marrow adipose tissue and hip and spine bone mineral density in African-American and Caucasian participants: the CARDIA study. J Clin Endocrinol Metab (2012) 97:1337-46. doi:10.1210/jc. 2011-2605
53. Shen W, Chen J, Gantz M, Punyanitya M, Heymsfield SB, Gallagher D, et al. Ethnic and sex differences in bone marrow adipose tissue and bone mineral density relationship. Osteoporos Int (2012) 23:2293-301. doi:10.1007/s00198011-1873- $\mathrm{x}$

54. Botolin S, McCabe LR. Bone loss and increased bone adiposity in spontaneous and pharmacologically induced diabetic mice. Endocrinology (2007) 148:198-205. doi:10.1210/en.2006-1006

55. Slade JM, Coe LM, Meyer RA, McCabe LR. Human bone marrow adiposity is linked with serum lipid levels not T1-diabetes. J Diabetes Complications (2012) 26:1-9. doi:10.1016/j.jdiacomp.2011.11.001

56. Sheu Y, Schwartz AV, Armati F, Goodpaster B, Li X, Bauer D, et al. Bone marrow adiposity is elevated in older men with type 2 diabetes. Program of the 72 nd Scientific Sessions of the American Diabetes Association. Philadelphia, PA (2012).

57. Ensrud KE, Ewing SK, Stone KL, Cauley JA, Bowman PJ, Cummings SR. Intentional and unintentional weight loss increase bone loss and hip fracture risk in older women. J Am Geriatr Soc (2003) 51:1740-7. doi:10.1046/j.1532-5415 2003.51558.x

58. Schwartz AV, Johnson KC, Kahn SE, Shepherd JA, Nevitt MC, Peters AL, et al. Effect of one year of an intentional weight loss intervention on bone mineral density in type 2 diabetes: results from the look ahead randomized trial. J Bone Miner Res (2012) 27:619-27. doi:10.1002/jbmr.1483

59. Bosy-Westphal A, Later W, Schautz B, Lagerpusch M, Goele K, Heller M, et al. Impact of intra- and extra-osseous soft tissue composition on changes in bone mineral density with weight loss and regain. Obesity (Silver Spring) (2011) 19:1503-10. doi:10.1038/oby.2011.40

60. Shen W, Chen J, Punyanitya M, Shapses S, Heshka S, Heymsfield SB. MRImeasured bone marrow adipose tissue: changes during weight loss and its relationship with DXA-measured bone mineral. FASEB J (2007) 21:831.838.

61. Schafer AL, Li X, Schwartz AV, Tufts LS, Wheeler AL, Grunfeld C, et al. Changes in vertebral bone marrow fat and bone mass after gastric bypass surgery: a pilot study. Bone (2015) 74C:140-5. doi:10.1016/j.bone.2015.01.010

62. Buchwald H, Estok R, Fahrbach K, Banel D, Jensen MD, Pories WJ, et al. Weight and type 2 diabetes after bariatric surgery: systematic review and meta-analysis. Am J Med (2009) 122(248-256):e245. doi:10.1016/j.amjmed.2008.09.041

63. Burge R, Dawson-Hughes B, Solomon DH, Wong JB, King A, Tosteson A. Incidence and economic burden of osteoporosis-related fractures in the United States, 2005-2025. J Bone Miner Res (2007) 22:465-75. doi:10.1359/jbmr.061113

64. Demontiero O, Vidal C, Duque G. Aging and bone loss: new insights for the clinician. Ther Adv Musculoskelet Dis (2012) 4:61-76. doi:10.1177/ 1759720X11430858

65. Rosen CJ, Klibanski A. Bone, fat, and body composition: evolving concepts in the pathogenesis of osteoporosis. Am J Med (2009) 122:409-14. doi:10.1016/j. amjmed.2008.11.027

Conflict of Interest Statement: The author declares that the research was conducted in the absence of any commercial or financial relationships that could be construed as a potential conflict of interest.

Received: 05 January 2015; accepted: 08 March 2015; published online: 30 March 2015. Citation: Schwartz AV (2015) Marrow fat and bone: review of clinical findings. Front. Endocrinol. 6:40. doi: 10.3389/fendo.2015.00040

This article was submitted to Bone Research, a section of the journal Frontiers in Endocrinology.

Copyright $\odot 2015$ Schwartz. This is an open-access article distributed under the terms of the Creative Commons Attribution License (CC BY). The use, distribution or reproduction in other forums is permitted, provided the original author(s) or licensor are credited and that the original publication in this journal is cited, in accordance with accepted academic practice. No use, distribution or reproduction is permitted which does not comply with these terms. 